Original Article

\title{
Graphene or carbon nanofiber-reinforced zirconia composites: Are they really worthwhile for structural applications?
}

\author{
Rafael Cano-Crespo ${ }^{\mathrm{a}}$, Bibi Malmal Moshtaghioun ${ }^{\mathrm{a}, \mathrm{b}}$, Diego Gómez-García ${ }^{\mathrm{a}, \mathrm{c}, *}$, Rodrigo Moreno ${ }^{\mathrm{d}}$, \\ Arturo Domínguez-Rodríguez ${ }^{\mathrm{a}}$ \\ ${ }^{a}$ Departamento de Física de la Materia Condensada, Universidad de Sevilla, Apartado 1065, 41080, Sevilla, Spain \\ ${ }^{\mathrm{b}}$ Instituto de Ciencia de Materiales de Aragón, CSIC-Universidad de Zaragoza, Sede Campus Río Ebro, Edificio Torres Quevedo, calle María de Luna 3, 50018 Zaragoza, \\ Spain \\ ${ }^{\mathrm{c}}$ Instituto de Ciencia de Materiales de Sevilla, CSIC-USE, Avenida Américo Vespucio 49, 41092, Sevilla, Spain \\ d Instituto de Cerámica y Vidrio, CSIC, E-28049, Madrid, Spain
}

\section{A R T I C L E I N F O}

\section{Keywords:}

Zirconia

Graphene oxide

Carbon nanofibers

Mechanical properties

Creep resistance

\begin{abstract}
A B S T R A C T
The use of allotropic phases of carbon (i.e. nanotubes, graphene or carbon nanofibers) as second phases to design ceramic composites is a hot topic at present. Researchers try to provide a remarkable improvement of the parent ceramic assuming that some of the outstanding mechanical properties of these phases migrate to the resultant composite. This reasonable idea has been questioned severely in the case of nanotubes addition but there is not any analysis for the other two phases cited previously. To elucidate this question, zirconia was selected as a model ceramic. This paper reports the mechanical properties of zirconia composites reinforced either with graphene or carbon nanofibers, with special emphasis on the high-temperature plasticity.
\end{abstract}

\section{Introduction}

Zirconia (3Y-TZP) and/or zirconia-based composites are interesting multifunctional materials that have been used for many applications, such as solid-oxide fuel cells, oxygen sensors and ceramic membranes, due to their good high-temperature stability, high breakdown electrical field or large energy bandgap [1]. These applications are due to its excellent properties: biocompatibility, high fracture toughness, high strength and low wear rates [2]. Monolithic 3YTZP has been extensively studied since last decades, and grain-boundary sliding GBS is recognized as being the primary deformation mechanism responsible for the high-temperature superplastic behavior accommodated by diffusion $[3,4]$.

A usual strategy to improve the properties and minimize their main drawback, i.e. their brittleness $[5,6]$ is through the design of ceramicceramic composites either by tailoring complex microarchitectures (as in the case of laminates and FGMs) or by reinforcing the matrix with the addition of a second phase [7].

There are several strategies to improve the mechanical properties of zirconia ceramics with a reinforcing second phase. For instance, doping with another cation: Bernardi-Martín et al. [8,9] studied the hightemperature plasticity of ceria-doped zirconia nanostructured polycrystals. Another approach has been the design of composites:
Calderón-Moreno et al. [10] studied the high temperature creep of alumina-zirconia composites. The use of nanocrystalline-based specimens was the strategy of Lorenzo-Martín et al. [11]. They studied the creep of nanocrystalline YTZP ceramics with a glassy phase and found grain boundary sliding as the deformation mechanism. They found that the mechanical behavior depends critically on the glassy phase content [12]. Another way to improve the mechanical properties of advanced ceramics materials is by addition of nanofibers (NF) in the so-called fiber-reinforced ceramic composites, which show significant improvements in toughness over monolithic ceramics. Fibers/whiskers usually have diameters in-between tens of nanometers to tens of micrometers and lengths around several micrometers to hundreds of micrometers, which are embedded inside a fine-grained ceramic matrix [13]. To this purpose, whiskers of a harder material such as SiC have been used traditionally. Calderón-Moreno et al. [14] studied the high-temperature deformation of $\mathrm{ZrO}_{2}-\mathrm{Al}_{2} \mathrm{O}_{3} / \mathrm{SiC}$ whisker composites.

In recent years graphene, the two dimensional array of a one-atom thick layer of carbon atoms arranged in a honeycomb lattice, is a promising candidate. Graphene has a large specific surface area $\left(2630 \mathrm{~m}^{2} \mathrm{~g}^{-1}\right)$, high intrinsic electron mobility $\left(2 \cdot 10^{5} \mathrm{~cm}^{2} \mathrm{v}^{-1} \mathrm{~s}^{-1}\right)$ $[15,16]$, high Young modulus $(\approx 1.0 \mathrm{TPa})$ [17], a fracture strength of $130 \mathrm{GPa}$ [18], thermal conductivity $\left(\approx 5000 \mathrm{~W} \mathrm{~m}^{-1} \mathrm{~K}^{-1}\right)$ [19], high optical transmittance $(\approx 97.7 \%)$ and therefore it is fine for applications

\footnotetext{
* Corresponding author at: Departamento de Física de la Materia Condensada, Universidad de Sevilla, Apartado 1065, 41080, Sevilla, Spain.

E-mail address: dgomez@us.es (D. Gómez-García).
} 
such as transparent conductive electrodes [20,21]. Chemically modified graphene has been studied in the context of many applications, such as polymer composites, energy-related materials, sensors, 'paper-like' materials, field-effect transistors, and biomedical applications [22,23]. Graphene platelets (GPLs) are formed by several layers of graphene with thickness of up to $100 \mathrm{~nm}$ [24] and called as graphene nanosheets, multilayer graphene nanosheets or graphene nanoplatelets (GNPs). Rincón et al. [25] have reported the mechanical properties and electrical conductivities of alumina-zirconia composites reinforced with either graphene oxide or carbon nanofibers. Their mechanical properties changed modestly, with slight decrease of hardness and a tiny increment of the fracture toughness. On the contrary, the electrical conductivity increases remarkably, reaching the maximum value for 2 vol\% graphene oxide concentration. Chen et al. [26] fabricated graphenereinforced zirconia ceramics using field-assisted sintering and reported a value of fracture toughness of $15.3 \mathrm{MPa} \mathrm{m}^{1 / 2}$, as tested by the singleedge notched beam method, which reflects an increase of $61 \%$ compared to GNPs-free 3Y-TZP. On the other hand, with higher GNPs content, the improvement in fracture toughness is limited. There is a tiny increment of hardness compared to the monolithic material. Shin et al. [27] sintered reduced graphene oxide reinforced yttria-stabilized zirconia composite ceramics by spark plasma sintering and reported that the hardness decreased slightly with reduced graphene oxide (RGO) addition, whereas the fracture toughness slowly increased from 4.4 to $5.9 \mathrm{MPa} \mathrm{m}^{1 / 2}$. The RGO pull-out and crack bridging contributed to the improved fracture toughness. Liu et al. [28] sintered zirconia toughened alumina (ZTA) adding GNPs as the secondary phase $(0.8 \mathrm{vol}$ $\%$ ) by SPS and obtained a value of fracture toughness of $9.05 \mathrm{MPa} \mathrm{m}^{1 / 2}$ ( $40 \%$ of increase respect to material without GNPs). On the other hand, the hardness decreased from $17.5 \mathrm{GPa}$ to $11.1 \mathrm{GPa}$ in the worst case. Rincón et al. [29] fabricated fully stabilized zirconia laminates comprising graphene oxide-enriched (GO) layers by colloidal processing and found that the presence of GO-rich layers stops the crack without deflection or bifurcation. The hardness was $17.6 \mathrm{GPa}$ for all layers.

Other carbon phases have been considered in literature with the aim of improving the mechanical properties of zirconia. Regarding carbon nanotubes (CNTs), a review reports the main achievements and limitations of this approach [30].

In the field of ceramic science, carbon nanofibers (CNFs) have been considered as a reinforcement phase in potential systems such as AlN [31] or in $\mathrm{Al}_{2} \mathrm{O}_{3}$ matrix ceramics at room temperature [32] and at high temperature [33] because of their superior advantages compared with single-walled or multi-walled carbon nanotubes; i.e. their low price and their good dispersibility. Carbon nanofiber-reinforced zirconia composites $\left(\mathrm{ZrO}_{2}-\mathrm{CNF}\right)$ have been the object of study and few results are reported in literature. Duszová et al. [34] sintered $\mathrm{ZrO}_{2}$-CNF and found a decrease in the values of Vickers hardness and fracture toughness as compared to monolithic $\mathrm{ZrO}_{2}$. Dusza et al. [35] achieved a decrease of hardness and fracture toughness for $\mathrm{ZrO}_{2}$-CNF sintered by hot pressing and spark plasma sintering with 2.0 and 3.3 vol.\% of CNFs respect to pure zirconia.

Until now, there is not a systematic study on the high-temperature plasticity of these composites. This work is aimed at covering this lack of information. A comparison between room-temperature performance and high-temperature creep is carried out, with special emphasis on the deformation mechanisms.

\section{Experimental procedure}

\subsection{Starting materials}

Tetragonal zirconia powder stabilized with $3 \%$ mol of $\mathrm{Y}_{2} \mathrm{O}_{3}$ (TZ3YSE, Tosoh, Japan) with an average particle size of $90 \mathrm{~nm}$ and a specific surface area of $6.7 \mathrm{~m}^{2} \mathrm{~g}^{-1}$, was used in this study. GO (Nanoinnova Tecnologies, Spain), with a length of $1-4 \mu \mathrm{m}$, a thickness of $0.7-1.2 \mathrm{~nm}$ and a surface area of $103 \mathrm{~m}^{2} / \mathrm{g}$ was used as secondary phase. CNFs (GANF - Grupo Antolin, Spain) with an outer diameter of $20-80 \mathrm{~nm}$, a length of more than $30 \mu \mathrm{m}$ and a surface area of $150-200 \mathrm{~m}^{2} \mathrm{~g}^{-1}$ were also used as secondary phase. For more details on the materials features, see $[36,37]$.

\subsection{Powder processing methods}

The colloidal stability of zirconia powder was studied measuring the zeta potential of diluted suspensions $\left(10^{-1} \mathrm{gl}^{-1}\right)$ prepared in deionized water as a function of deflocculant content, using an ammonium salt of polyacrylic acid (PAA, Duramax D3005, Rohm \& Haas, USA) as a deflocculant. For the dispersion of CNFs in water a copolymer of polyacrylic acid with polethyleneglycol (Hypermer KD 7, Uniqema, UK) was used. GO readily disperses in water without the addition of any deflocculant [36].

Zeta potential measurements were performed by laser Doppler velocimetry (Zetasizer NanoZS, Malvern, UK). $\mathrm{KCl} 10^{-2} \mathrm{M}$ was used as inert electrolyte to maintain the ionic strength. Suspensions for zeta potential measurements were prepared by mechanical agitation during 20 min followed by $1 \mathrm{~min}$ sonication (dr Hielscher, UP400S, Germany). $\mathrm{pH}$ was maintained at $\mathrm{pH} 9-10$, which is the natural $\mathrm{pH}$ of zirconia suspensions, while in the case of CNFs that $\mathrm{pH}$ was reached adding tetramethylammonium hydroxide (TMAH).

Concentrated suspensions of zirconia with GO and with CNFs were prepared to a solids loading of $35 \mathrm{vol} . \%$ using the optimized contents of deflocculant and different sonication times. The suspensions were prepared by dispersing first the CNFs or the GO in water with 2 min sonication. In a second step zirconia was added and sonicated for different times in order to determine the optimum sonication time. Rheological measurements were performed using a rotational rheometer (MARS, Thermo Haake, Karlsruhe, Germany) under controlled shear rate conditions at $25{ }^{\circ} \mathrm{C}$ and using a double-cone and plate measuring system.

The optimized suspensions were frozen in a rotatory chamber using liquid nitrogen as refrigerant $\left(-196^{\circ} \mathrm{C}\right)$. The frozen suspensions were introduced in a freeze-dryer (CRYODOS-50, Telstar, Spain) for $24 \mathrm{~h}$. The condensator temperature was $-50^{\circ} \mathrm{C}$, and the conditions of the storage camera were $20{ }^{\circ} \mathrm{C}$ and $0.050 \mathrm{mbar}$ [36]. The resultant mixtures of powders contained 98 vol.\% of zirconia (Z) and 2 vol.\% of either GO or CNFs (e.g. $0.5 \mathrm{wt} \%$ ). Those mixtures are denoted in this study as Z$\mathrm{GO}$ and Z-CNF, respectively.

As a reference material the as-received pure zirconia commercial powders without any treatment were used. This powder is denoted as Z.

\subsection{Sintering}

Bulk composite samples were sintered using a SPS process (Dr. Sinter Lab Inc., Model 515 S, Kanagawa, Japan (pulsed high DC current $20 \mathrm{~V}, 0-1500$ composite samples were sintered using a SPS A)). The powder mixtures were poured into a graphite die of $20 \mathrm{~mm}$ in diameter. A sheet of graphitic paper was placed between the punch and the powder and between the die and the powder for easy removal of the sintered sample. The sintering process was conducted under a vacuum of 4-6 Pa. A uniaxial pressure of $75 \mathrm{MPa}$ was applied throughout the sintering cycle. The sintering temperature was increased to $1300^{\circ} \mathrm{C}$ at a rate of $100^{\circ} \mathrm{C} / \mathrm{min}$. The holding time was $5 \mathrm{~min}$. The temperature was measured and controlled using an optical pyrometer. Shrinkage, displacement, heating current, and voltage were also recorded during the sintering process. The bulk density of the samples was measured by the Archimedes method with distilled water as the immersion medium using $6.10,2.1$ and $2.1 \mathrm{~g} / \mathrm{cm}^{3}$ as densities of zirconia, GO and CNFs, respectively.

\subsection{Microstructural characterization}

Raman spectroscopy (Model LabRAm Horiba Jobin Yvon, Horiba 
Ltd, Kyoto, Japan) was carried out in order to study the integrity of GO and CNFs before and after sintering and also before and after the creep experiments. Measurements were done with a green laser (He-Ne $532.14 \mathrm{~nm}$ ), $20 \mathrm{~mW}, 600 \mathrm{~g} / \mathrm{mm}$ grating without filter. A $100 \times$ objective and a confocal pinhole of $100 \mu \mathrm{m}$ were used. The range of Raman shift was in-between 200 and $3500 \mathrm{~cm}^{-1}$. The Raman spectrometer was calibrated using a silicon wafer.

The microstructure of the samples was examined by high-resolution scanning electron microscopy HRSEM (Model HITACHI S5200, Hitachi High-Technologies Corporation, Tokyo, Japan) in the mode of secondary electrons. Surfaces were first grounded and then polished with diamond paste down to $1 \mu \mathrm{m}$. These polished surfaces were prepared to characterize the zirconia grain boundaries and to this end they were thermally etched at $1150{ }^{\circ} \mathrm{C}$ for $15 \mathrm{~min}$ in argon atmosphere. The grain morphology characterization was described by measuring the equivalent planar diameter $\left[\mathrm{d}=(4 \mathrm{area} / \pi)^{1 / 2}\right]$, and the shape factor $\left.[\mathrm{F}=4 \pi \text { area/(perimeter })^{2}\right]$ from HRSEM micrographs.

\subsection{Hardness and fracture toughness determination}

The hardness and fracture toughness of the specimens were measured by means of the indentation technique (Buehler, model Micromet 5103) with a conventional diamond pyramid indenter. The applied load (98N for $10 \mathrm{~s}$ ) was used according to the standard ASTM E92-72. An optical confocal microscope (Leica DCM-3D, Wetzlar, Germany) was used in order to study form and length of indentions and cracks.

\subsection{High-temperature mechanical tests}

The mechanical behavior of the processed materials was investigated by means of uniaxial compression creep tests on samples cut and grounded as parallelepipeds of approximate dimensions $5 \mathrm{~mm} \times 2.5 \mathrm{~mm} \times 2.5 \mathrm{~mm}$. The creep tests were performed on a prototype creep machine at $1200^{\circ} \mathrm{C}$ and $1250{ }^{\circ} \mathrm{C}$, stresses ranging between 9 and $49 \mathrm{MPa}$ and in a controlled argon atmosphere to avoid the combustion of GO and CNFs. The temperature interval was high enough to ensure that steady-state creep were reached but sufficiently small to avoid significant grain growth. The working atmosphere was prepared at room temperature using several vacuum cycles $\left(10^{-6} \mathrm{~Pa}\right)$ followed by the introduction of argon. These cycles were repeated at $350{ }^{\circ} \mathrm{C}$ to eliminate any products of possible degassing of the elements inside the working chamber. Once reached the testing temperature $\left(1200^{\circ} \mathrm{C}\right)$ and after thermal stabilization of the system, stress changes were made and a steady state characterized by a constant strain rate was obtained for each experimental condition. The creep curves were analyzed using the standard phenomenological Dorn equation:

$\dot{\varepsilon}=A \frac{\sigma^{n}}{d^{p}} \exp \left(-\frac{Q}{k T}\right)$

where $\mathrm{A}$ is a stress and temperature independent term reflecting the dependence of the strain rate on the microstructural features of the material (composition, amount and physical properties of glassy phases, grain morphology, etc.), $\sigma$ the applied stress, $d$ the mean grain size, $\mathrm{k}$ the Boltzmann's constant, and $\mathrm{T}$ the absolute temperature. The parameters $\mathrm{n}, \mathrm{p}$ and $\mathrm{Q}$ (generically known as creep parameters) are, respectively, the stress and grain size exponents, and the apparent activation energy for creep. These parameters together with the microstructural changes after deformation are the fingerprints of the deformation mechanisms.

\section{Results and discussion}

The zeta potential of the starting powders as a function of the deflocculant content can be seen in Fig. 1. Zirconia and GO powders were dispersed with polyacrylate (Duramax D3005) whereas CNFs were dispersed with the copolymer Hypermer KD7. The zirconia curve shows

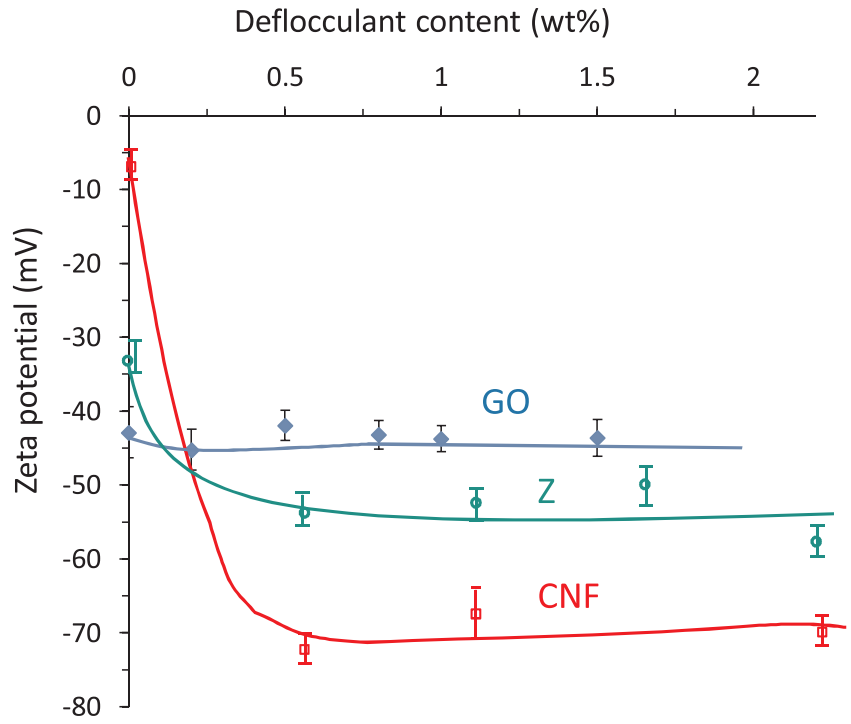

Fig. 1. Variation of zeta potential with deflocculant content for aqueous suspensions of zirconia, GO and CNFs. Zirconia and GO were dispersed with PAA and CNFs with the copolymer Beycostat.

a

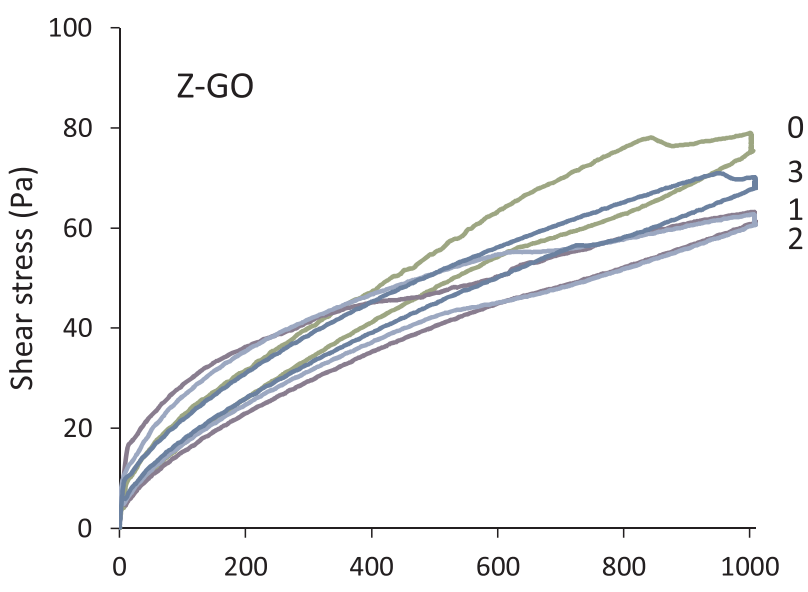

Shear rate $\left(\mathrm{s}^{-1}\right)$

b

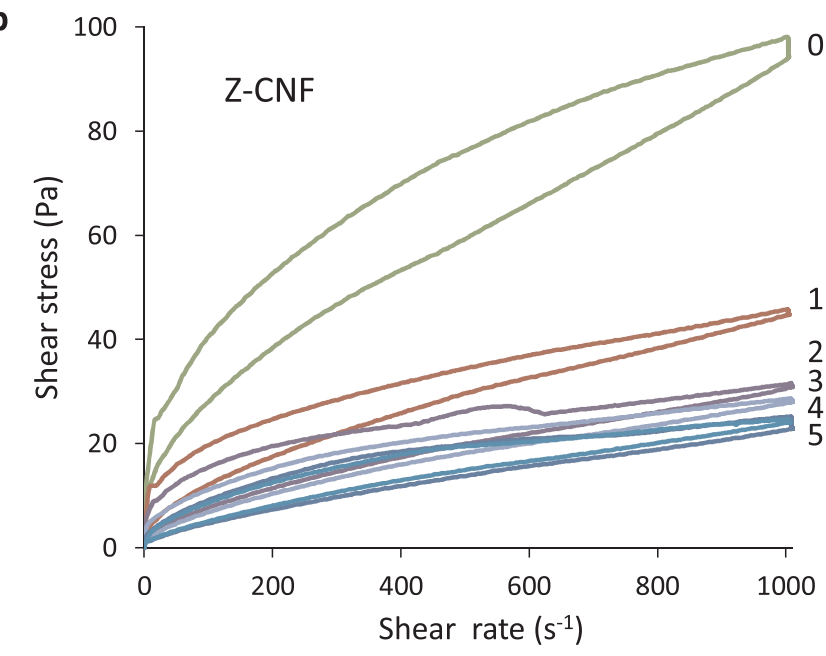

Fig. 2. Flow curves of suspensions of (a) ZrO2-GO and (b) ZrO2-CNFs prepared to 35 vol.\% solids and different sonication times. 


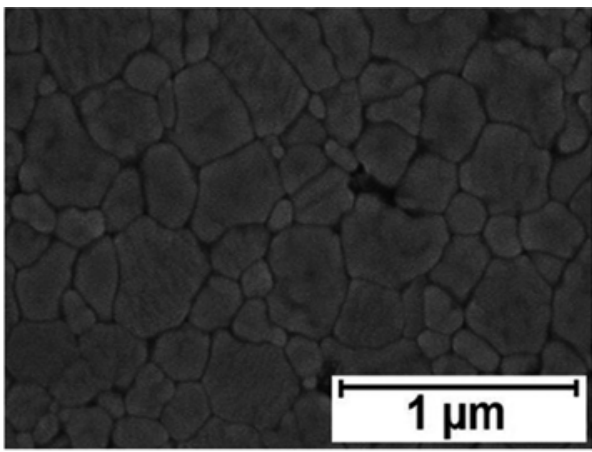

(a)

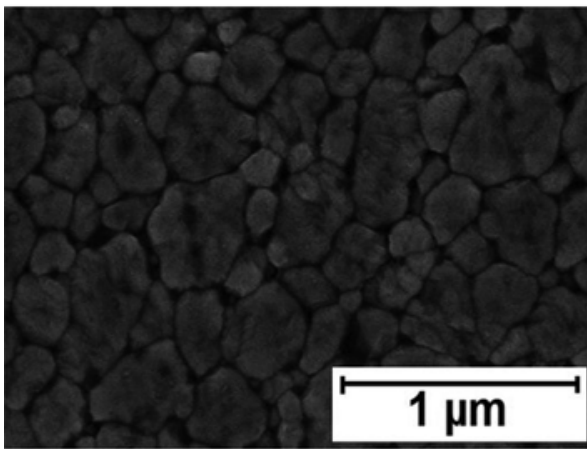

(c)

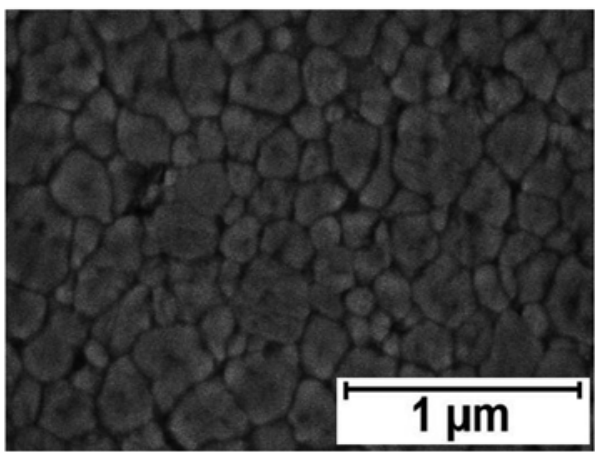

(e)

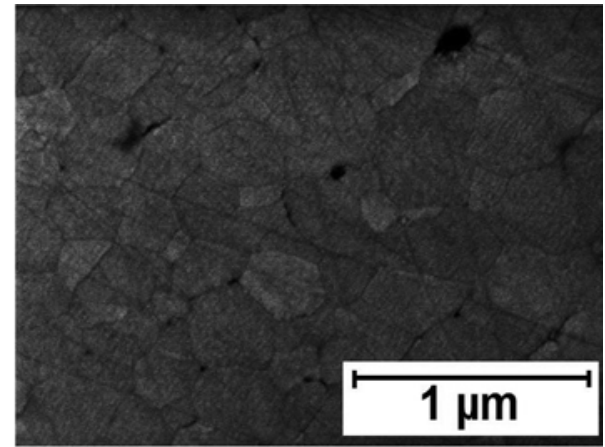

(b)

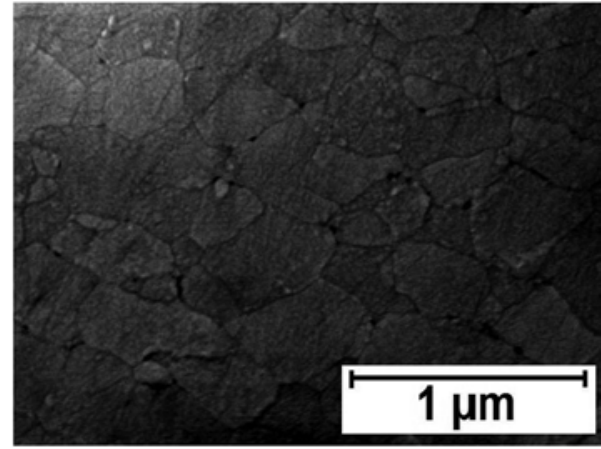

(d)

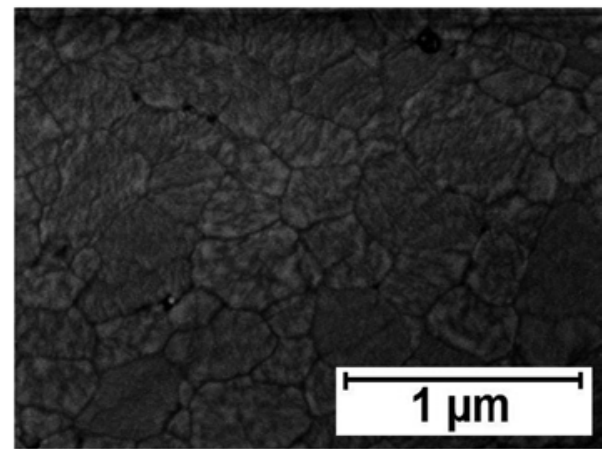

(f)

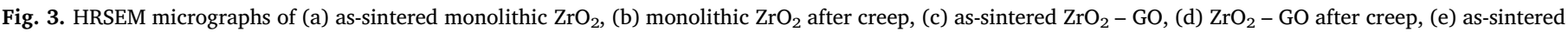
$\mathrm{ZrO}_{2}-\mathrm{CNFs}$ and (f) $\mathrm{ZrO}_{2}-\mathrm{CNFs}$ after creep.

Table 1

Raman shifts (in $\mathrm{cm}^{-1}$ ) of the characteristic peaks in the Raman spectra of the sets of materials studied in this work.

\begin{tabular}{|c|c|c|c|c|c|c|c|c|}
\hline & $\mathrm{ZrO}_{2}$ peak & $\mathrm{ZrO}_{2}$ peak & $\mathrm{ZrO}_{2}$ peak & $\mathrm{ZrO}_{2}$ peak & D peak & G peak & 2D peak & $D+G$ peak \\
\hline GO powder & & & & & 1367 & 1601 & & \\
\hline CNF powder & & & & & 1353 & 1583 & 2699 & \\
\hline Z-GO powder & 262 & 331 & 472 & 641 & 1350 & 1605 & 2648 & 2926 \\
\hline Z-GO sintered specimen & 264 & 322 & 467 & 645 & 1362 & 1599 & 2717 & 2952 \\
\hline Z-GO after creep & 264 & 329 & 472 & 648 & 1360 & 1590 & 2709 & 2932 \\
\hline Z-CNF powder & 256 & 320 & 463 & 638 & 1351 & 1583 & 2693 & 2917 \\
\hline Z-CNF sintered specimen & 264 & 326 & 470 & 645 & 1356 & 1589 & 2706 & 2957 \\
\hline Z-CNF after creep & 265 & 334 & 482 & 647 & 1350 & 1586 & 2703 & 2926 \\
\hline
\end{tabular}

that the addition of $0.5 \mathrm{wt} \%$ of polyelectrolyte improves the stability with an increase of zeta potential from $-30 \mathrm{mV}$ to about $-50 \mathrm{mV}$. The addition of only $0.5 \mathrm{wt} \%$ polyelectrolyte leads to a very high zeta potential absolute value and thus very high stability. The variation of zeta potential of GO with the same polyelectrolyte was reported in a previous work [36], in which it was shown that GO is very stable in water with zeta potential values of more than $-40 \mathrm{mV}$ and maintains the same value with polyelectrolyte additions. Finally, the suspension of CNFs without polyelectrolyte has a near to zero zeta potential so that the addition of a deflocculant is necessary to provide stability which in fact increases dramatically with only $0.5 \mathrm{wt} \%$ of the selected deflocculant. 


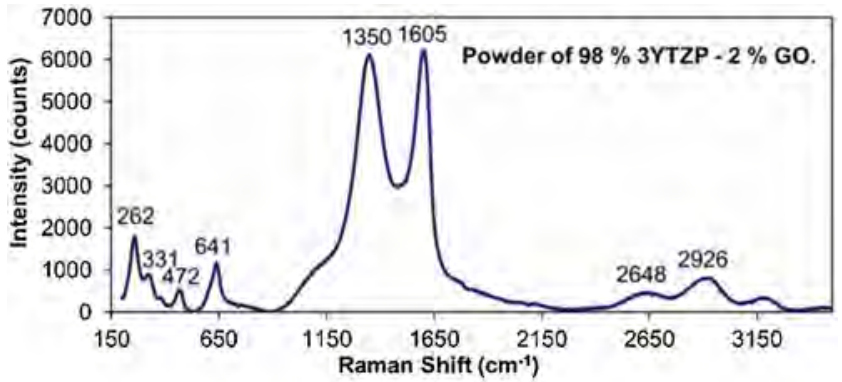

(a)

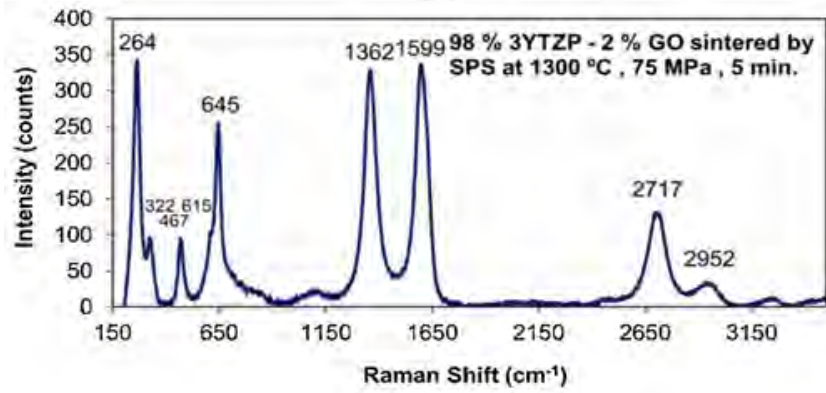

(b)

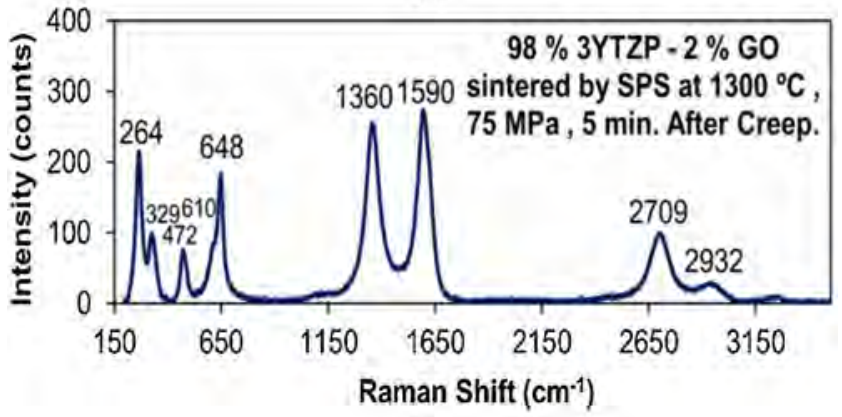

(c)

Fig. 4. Raman spectra of (a) powder of $\mathrm{ZrO}_{2}-\mathrm{GO}$, (b) sample of $\mathrm{ZrO}_{2}-\mathrm{GO}$ before creep and (c) sample of $\mathrm{ZrO}_{2}-\mathrm{GO}$ after creep deformation.

Concentrated suspensions of $\mathrm{ZrO}_{2}-\mathrm{GO}$ and $\mathrm{ZrO}_{2}-\mathrm{CNF}$ s were prepared to a solids content of $35 \mathrm{vol} . \%$ using $0.5 \mathrm{wt} \%$ PAA on a dry solids basis. CNFs were dispersed with $1 \mathrm{wt} \%$ Hypermer KD7 while GO did not require deflocculant. Fig. 2 shows the flow curves measured for both suspensions prepared at different sonication times. It can be seen that as-prepared suspensions, i.e. without sonication treatment, give high viscosities with broad thixotropic cycles. The suspension $\mathrm{ZrO}_{2}$-GO has the lowest viscosity after 2 min sonication although some thixotropy still remains. In the case of $\mathrm{ZrO}_{2}$-CNFs suspension both the viscosity and the thixotropy decrease with increasing sonication up to a $5 \mathrm{~min}$ treatment after which the viscosity is significantly lower than that of the $\mathrm{ZrO}_{2}$-GO suspension as well as the thixotropy, which does not completely disappear.

Suspensions $\mathrm{ZrO}_{2}-\mathrm{GO}$ and $\mathrm{ZrO}_{2}-\mathrm{CNFs}$ sonicated for 2 and $5 \mathrm{~min}$, respectively, were selected for freeze drying and further sintering by SPS at $1300^{\circ} \mathrm{C}$. The relative density of all the sintered samples was about $99 \%$ of theoretical, a necessary requirement to assess the reproducibility of the mechanical tests.

Fig. 3 shows SEM images of the polished surface of monolithic zirconia, $\mathrm{ZrO}_{2}$-GO and $\mathrm{ZrO}_{2}$-CNFs composites, prior to and after creep. In all the cases the shape factor is constant and equal to $\sim 0.7$ and the grain size is also constant and equal to $\sim 0.2-0.3 \mu \mathrm{m}$, so the morphology of the grains kept constant while creeping and also the microstructure of the studied materials.

Raman scattering is a very adequate technique for characterization

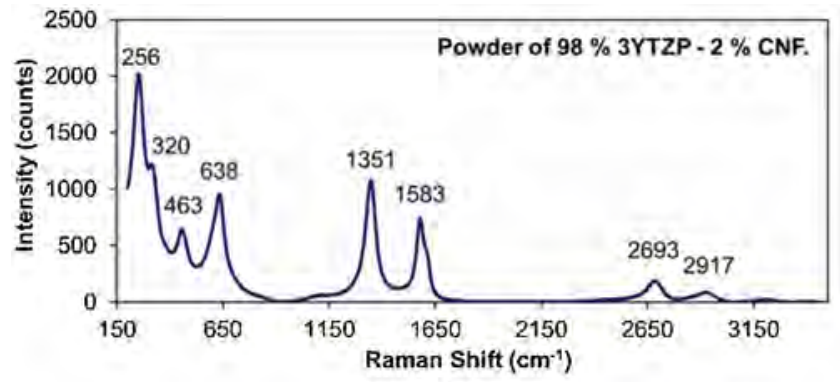

(a)

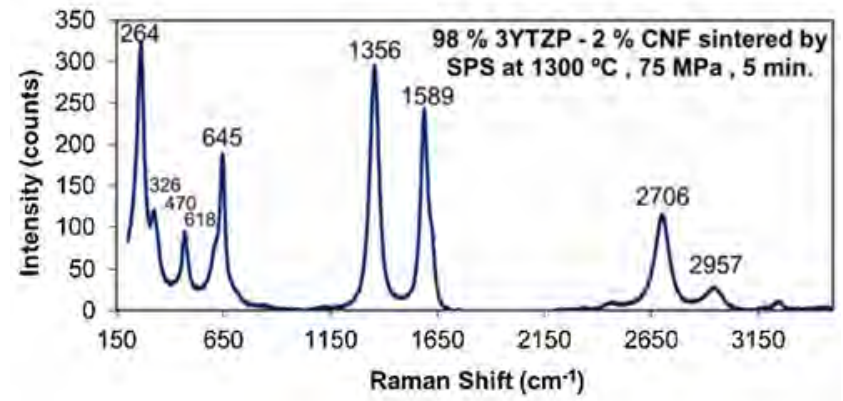

(b)

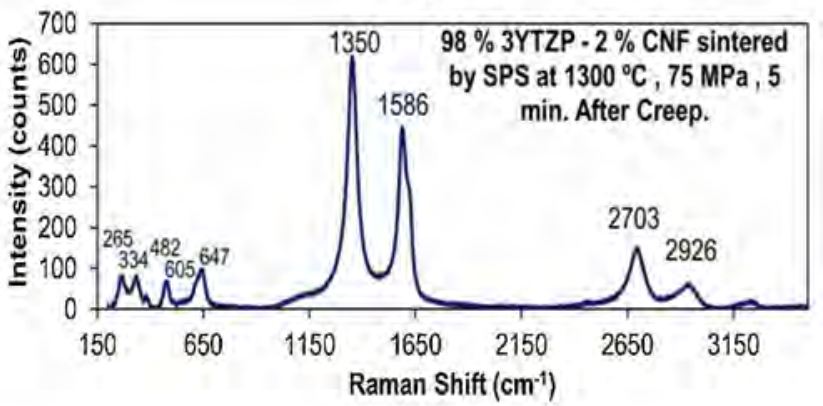

(c)

Fig. 5. Raman spectra of (a) powder of $\mathrm{ZrO}_{2}-\mathrm{CNFs}$, (b) sample of $\mathrm{ZrO}_{2}-\mathrm{CNFs}$ before creep and (c) sample of $\mathrm{ZrO}_{2}-\mathrm{CNF}$ after creep deformation.

of carbon-based materials. Numerical values of the characteristic peaks of the studied materials are provided in Table 1. Fig. 4. displays the Raman spectra of the starting powder of zirconia and graphene oxide, the sample sintered by SPS from this starting powder and the same sample after creep deformation. The four first peaks correspond to tetragonal zirconia $[38,39]$, the third peak corresponds to the D mode $\left(1350 \mathrm{~cm}^{-1}\right)$ and it is due to longitudinal optical phonons from the vicinity of the $k$-point in the Brillouin zone. The $\mathrm{G}$ mode $\left(\sim 1550-1600 \mathrm{~cm}^{-1}\right)$ corresponds to the tangential shear mode of carbon atoms. The second order band $2 \mathrm{D}$ is observed around $2700 \mathrm{~cm}^{-1}$ and it is related with the numbers of layers of graphene or GO [40,41]. Our Raman spectra are compatible with these features. The position of peaks in the Raman spectra of Fig. 4b differs from Fig. 4a, this is an evidence of the fact that graphene oxide is partially reduced and the crystal structure is distorted [41]. Fig. 5 displays Raman spectra of the starting powder of zirconia and CNFs together with the spectra of the sample sintered by SPS from this starting powder and the same sample after creep deformation. For comparison we can see that the position of the peaks is more or less the same. Thus, the integrity of the CNFs in these composites is assessed.

The ratios $\mathrm{I}_{\mathrm{D}} / \mathrm{I}_{\mathrm{G}}$ for the initial powders, the sintering specimens prior to and after the creep deformation are collected in Table 2. They give some quantitative information on the degree of degradation of GO and CNFs. According to these values, most carbon phases are preserved in the composite materials. 
Table 2

Ratio of the intensities of the D and G peaks for the sets of materials showing the degree of degradation of the carbon phases.

\begin{tabular}{ll}
\hline Specimen & $\mathrm{I}_{\mathrm{D}} / \mathrm{I}_{\mathrm{G}}$ \\
\hline GO powder & $0.96 \pm 0.03$ \\
CNF powder & $1.00 \pm 0.08$ \\
Z-GO powder & $0.98 \pm 0.01$ \\
Z-GO sintered specimen & $0.96 \pm 0.01$ \\
Z-GO after creep & $0.93 \pm 0.01$ \\
Z-CNF powder & $1.46 \pm 0.01$ \\
Z-CNF sintered specimen & $1.22 \pm 0.01$ \\
Z-CNF after creep & $1.39 \pm 0.01$ \\
\hline
\end{tabular}

As commented previously, the hardness and toughness of the specimens were measured by means of the indentation technique. The diagonals of each indentation are displayed in Fig. 6a-c. Length of cracks (c) and length of the imprint (a) were measured and their average values are shown in the Table 3. For Palmqvist cracks the value of $c / a \leq 2.5$ and $0.25<l / a<2.5(c / a=l / a+1)$. In this study $c /$ $a \approx 2.3$ and $l / a \approx 1.3$ and therefore the indentations are Palmqvist cracks. Laugier et al. [42] proposed a model to evaluate the fracture toughness in the case of Palmqvist cracks:

$K_{I C}=0.015\left(\frac{l}{a}\right)^{-1 / 2}\left(\frac{E}{H}\right)^{2 / 3} \frac{P}{c^{3 / 2}}$

Where $K_{I C}$ is the fracture toughness, $\mathrm{E}$ is the Young modulus, $\mathrm{H}$ is the hardness (determined from the load and the size of the indentation imprint), $\mathrm{P}$ is the applied load and $\mathrm{c}$ the crack length.

Table 3 displays the values of hardness and fracture toughness for all the sample sets considered in this work. All the composites of zirconia exhibit systematically lower hardness compared to that of pure zirconia. In contrast, the final fracture toughness is the same as the one measured in the monolithic zirconia within experimental uncertainty. These values are in reasonable agreement with those reported by Shin et al. [27] in their $\mathrm{ZrO} 2-\mathrm{GO}$ composites. These authors report values inbetween 4.4-5.9 $\mathrm{MPa} \mathrm{m}^{1 / 2}$ determined by the same method used in the present work. The dependence with the amount of graphene is weak in the range from 0.5 to 2 vol\%. The GO pull-out and crack bridging contributed to the improved fracture toughness. However, the reported values of hardness by these authors are smaller $(\approx 11.5 \mathrm{GPa})$. Regarding the $\mathrm{ZrO}_{2}$-CNFs composite, the hardness measured in our SPS specimens $14.7 \mathrm{GPa}$ is $64 \%$ higher than those reported by Dusza et al. [35], also sintered by SPS and 55\% higher than reported by these authors sintered by hot pressing. The same authors measured the fracture toughness and found similar results that in this study, but $18 \%$ higher in the case of their composite sintered by SPS.

When comparing critically the $\mathrm{ZrO}_{2}$-GO composites with the $\mathrm{ZrO}_{2}$ CNFs ones, it is possible to conclude that there is not a significant advantage in using graphene oxide for mechanical properties enhancement, at least for the concentration that it is expected to provide the optimal mechanical response. Within the limits of the experimental scatter, CNFs are more efficient to this end.

Fig. 7. Shows the creep curves at $1200^{\circ} \mathrm{C}$ and $1250{ }^{\circ} \mathrm{C}$ for $\mathrm{ZrO}_{2}-\mathrm{GO}$ (Fig. 7a) and $\mathrm{ZrO}_{2}$-CNFs (Fig. 7b). The creep curve of pure zirconia is omitted for the sake of simplicity. The applied stresses and temperatures are provided for each stage, as well as the values of the apparent activation energies $(Q)$ and stress exponents $(n)$. The stress exponents are in-between 2.5 and 3.0 in both composites and the activation energy is approximately $700 \mathrm{~kJ} / \mathrm{mol}$. There is good reproducibility of the creep parameters for different stages at different strain levels. Furthermore, this is consistent with the no degradation of the carbon phase during creep.

The stress exponents in pure zirconia specimens are systematically lower than those found in the carbon-based composites. This is

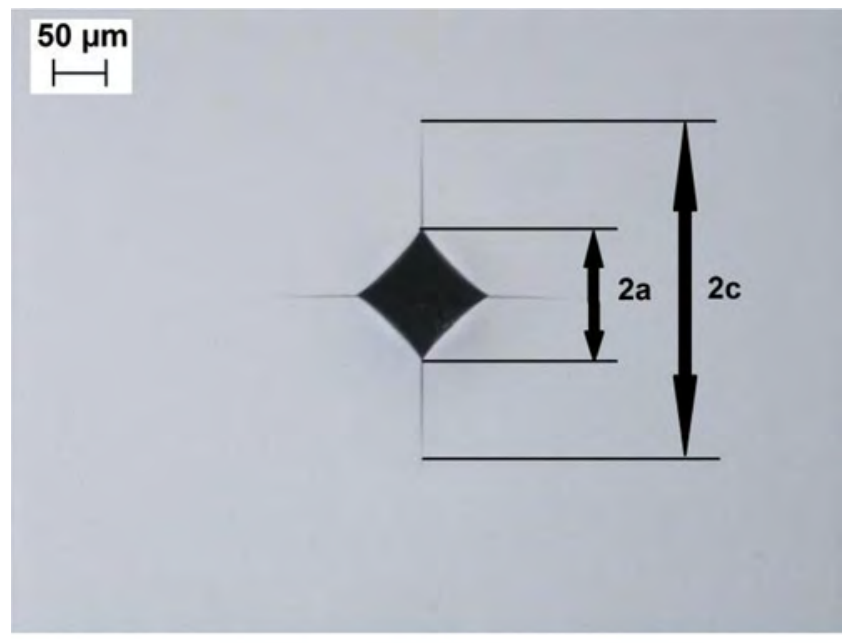

(a)

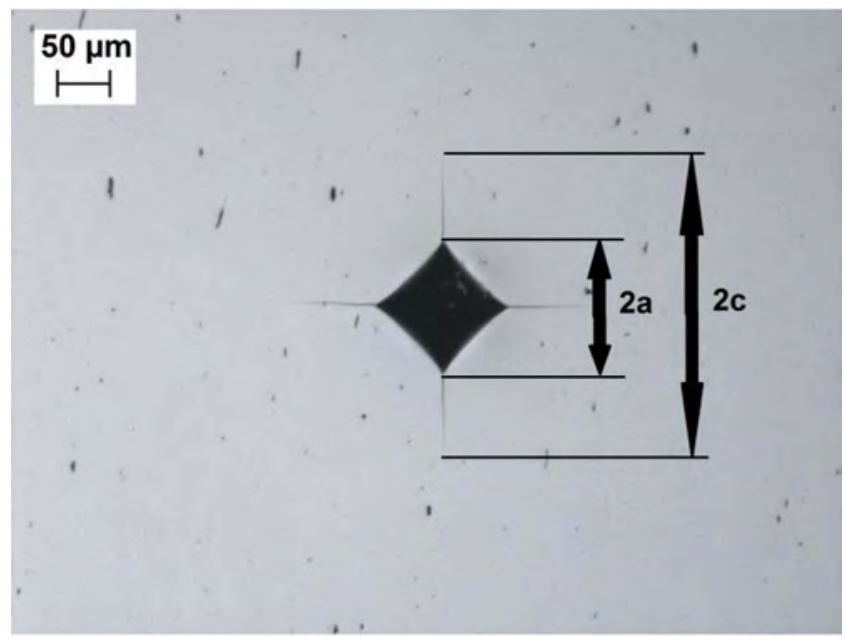

(b)

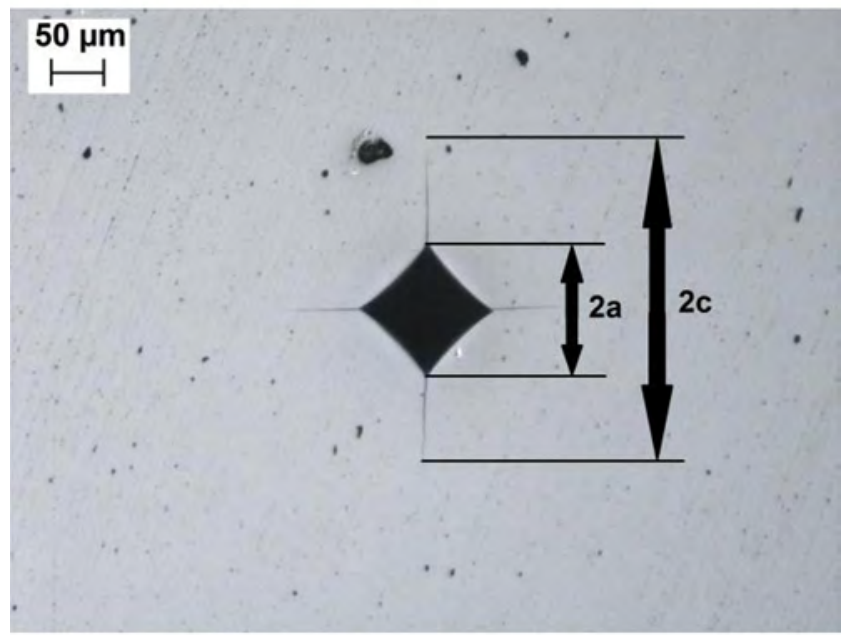

(c)

Fig. 6. Indentation imprints corresponding to the pure zirconia (a), $\mathrm{ZrO}_{2}-\mathrm{GO}$ (b) and $\mathrm{ZrO}_{2}$-CNFs (c) composites. 
Table 3

Lengths of indentation imprints, hardness and fracture toughness for the samples considered in this paper.

\begin{tabular}{lllll}
\hline & $2 \mathrm{a}(\mu \mathrm{m})$ & $2 \mathrm{c}(\mu \mathrm{m})$ & Hardness $(\mathrm{GPa})$ & $\begin{array}{l}\text { Fracture Toughness } \\
\left(\mathrm{MPa} \mathrm{m}{ }^{1 / 2}\right)\end{array}$ \\
\hline $\mathrm{ZrO}_{2}$ & $112 \pm 1$ & $264 \pm 2$ & $15.7 \pm 0.2$ & $4.6 \pm 0.1$ \\
$\mathrm{ZrO}_{2}$-GO & $114 \pm 1$ & $260 \pm 6$ & $15.0 \pm 0.2$ & $5.0 \pm 0.3$ \\
$\mathrm{ZrO}_{2}$-CNFs & $115 \pm 1$ & $257 \pm 6$ & $14.7 \pm 0.2$ & $5.3 \pm 0.3$ \\
\hline
\end{tabular}

consistent with a general model developed in literature for the stress exponent dependence on the grain size during grain boundary sliding accommodated by diffusion, which have been validated in yttria-stabilized zirconia and alumina ceramics [43]. One remarkable feature which must be pointed out is the large ductility of these ceramic composites. Fig. 7a and b display two creep curves in which the final strain is $\sim 60 \%$, without any microstructural evolution. Moreover, the final porosity is systematically lower than $2 \%$.

These features, together with the invariance of the grain distribution and size, permits to conclude that the deformation must be grain boundary sliding accommodated by diffusion of the lowest species in zirconia [43]. The GO or the CNFs just reduce the grain mobility for mutual sliding but they do not change diffusion along the boundaries, i.e. the accommodation mechanism.

In order to compare the creep resistance induced by these two carbon phases, strain rate versus stress are displayed in Fig. 8a and b. The experimental data fit to linear plots, in good consistency with the validity of the power-law proposed in the Dorn equation. The stress exponents obtained from the slopes of these fitting straight lines are in good agreement with those obtained through incremental changes of stress during creep. In general terms, it can be stated that monolithic zirconia is more creep resistant than $\mathrm{ZrO}_{2}-\mathrm{GO}$ or $\mathrm{ZrO}_{2}$-CNFs composites. However, such difference in creep resistance depends drastically on the working temperature. When temperature increases, both composites tend to have similar creep properties. For both temperatures employed the creep resistance for both composites differs in less than half an order of magnitude to creep resistance of monolithic zirconia. Therefore, for intermediate and very high-temperature applications,

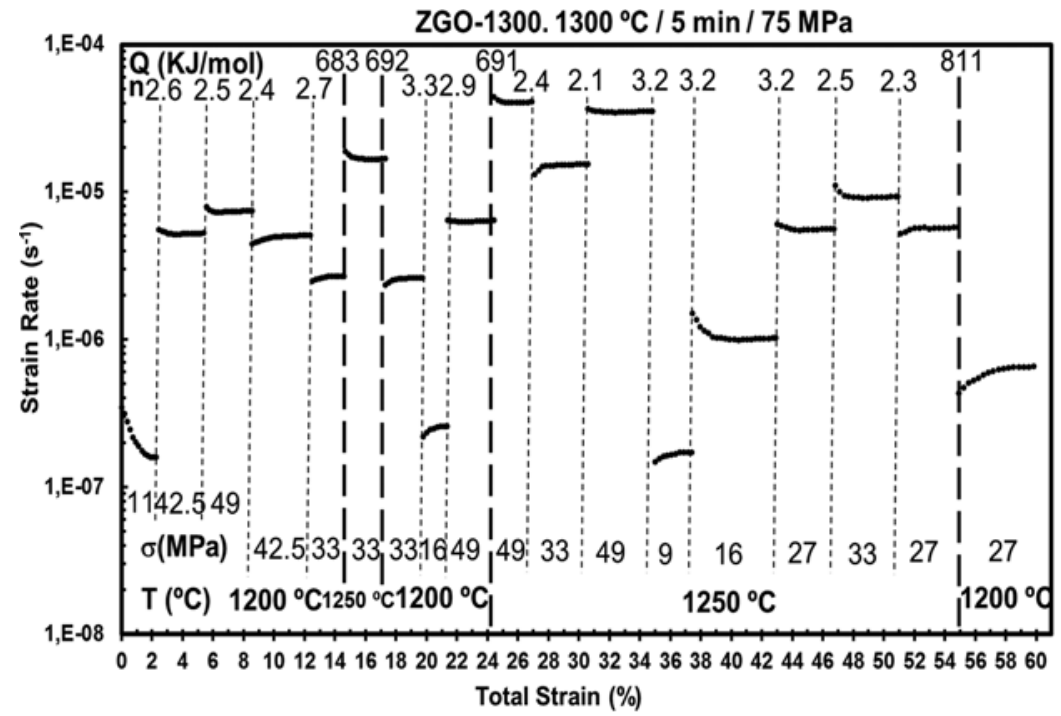

(a)

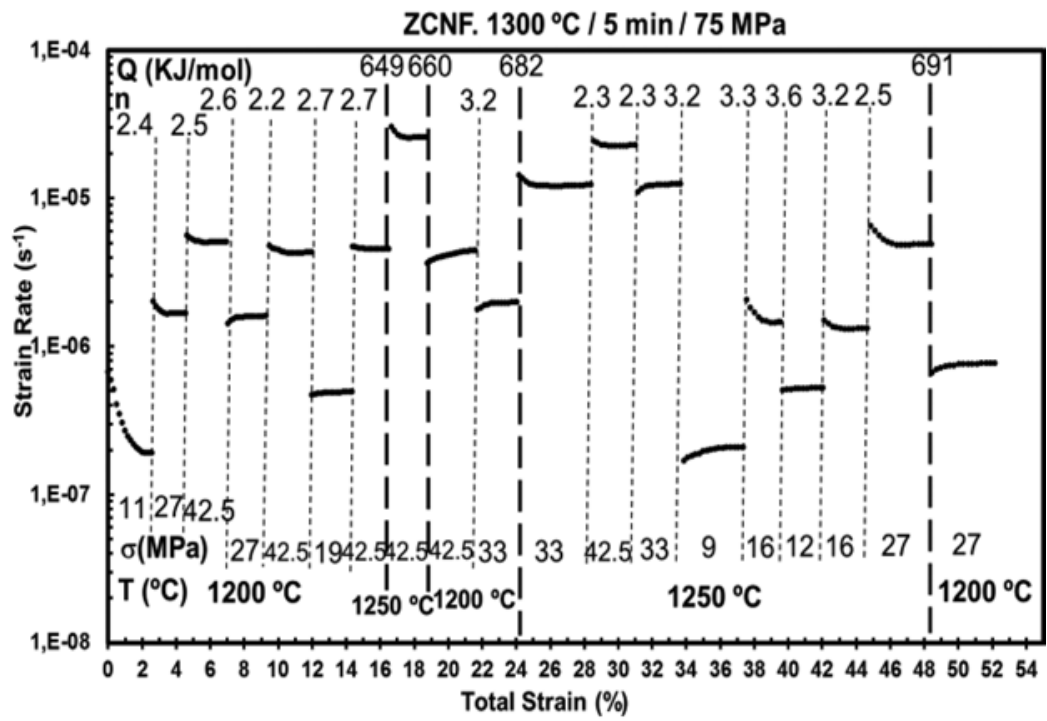

(b)

Fig. 7. Creep curves of (a) $\mathrm{ZrO}_{2}-\mathrm{GO}$ and (b) $\mathrm{ZrO}_{2}-\mathrm{CNFs}$ at $1200^{\circ} \mathrm{C}$ and $1250^{\circ} \mathrm{C}$. Creep equation is used to determine the stress exponents (n) and also the apparent activation energies $(Q)$. 


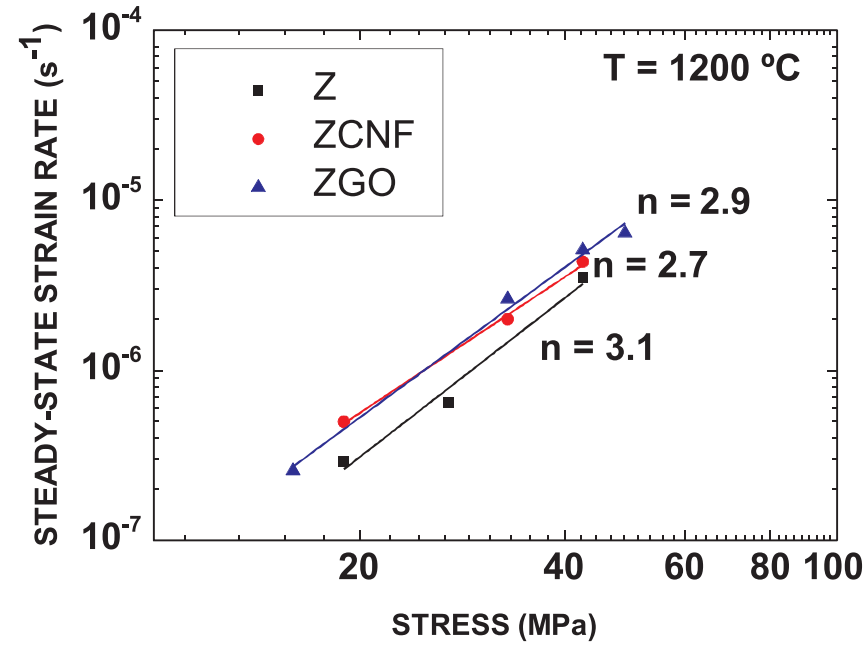

(a)

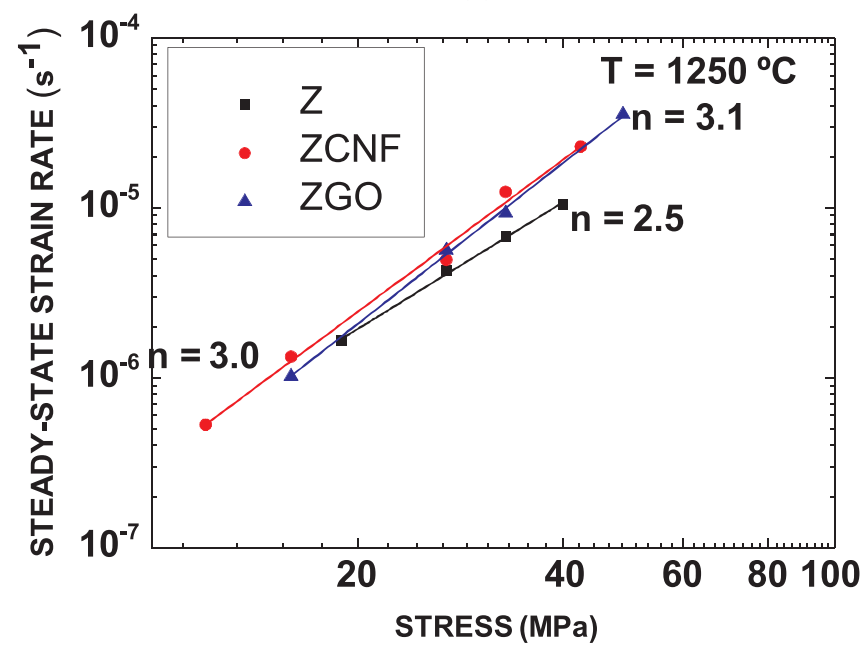

(b)

Fig. 8. Steady-state creep rate versus applied uniaxial compressive stress data for monolithic $\mathrm{ZrO}_{2}, \mathrm{ZrO}_{2}-\mathrm{GO}$ and $\mathrm{ZrO}_{2}-\mathrm{CNFs}$ at (a) $1200{ }^{\circ} \mathrm{C}$ and (b) $1250{ }^{\circ} \mathrm{C}$.

graphene and CNFs cannot provide an effective creep resistance to zirconia. Since creep is controlled by grain boundary sliding in all the cases, it is clear that the grain mobility in monolithic zirconia is much smaller than the same quantity in both composites, so it seems that graphene-oxide and also carbon-nanofibers work as lubricant between grain boundaries.

These latter results, together with the room-temperature values for hardness and fracture toughness show that graphene or CNFs do not provide a remarkable improvement of mechanical properties of zirconia polycrystals. The intrinsic outstanding mechanical properties of these carbon phases are not transferred to the zirconia composite, because the dominant effect seems to be a sort of lubricant effect or increase of grain boundary mobility.

In summary, these zirconia composites are not an excellent choice for the search of a significant improvement of mechanical properties. Further studies should be conducted to go insight into the sintering procedure to ensure that carbon phases distribute really homogeneously and they do not play a mere role of lubricant when the composite is subjected to mechanical stresses. To our knowledge, the problem of a real reproducibility and homogeneity of the carbon phases is the key ingredient which explains the large scattering and the discrepant results in literature. Our work shows that, at least this conventional route does not provide real advantageous composites.

\section{Conclusions}

Homogeneous mixtures of zirconia with $2 \%$ of GO or and CNFs have been obtained from concentrated aqueous suspensions after rheological optimization and subsequent freeze drying. Fully-dense $\mathrm{ZrO}_{2}-\mathrm{GO}$ and $\mathrm{ZrO}_{2}$-CNFs composites have been fabricated by SPS.

The analysis of the room-temperature hardness and fracture toughness allows concluding that both phases give rise to a similar mechanical response with a slight advantage for the $\mathrm{ZrO}_{2}$-CNFs composite for fracture toughness.

Furthermore, high-temperature creep behavior of those composites have been carried out and compared with the creep behavior of monolithic zirconia.

The ductility of the composites is quite remarkable: final strain as high as $60 \%$ are currently found at $1200-1250{ }^{\circ} \mathrm{C}$ with no microstructural evolution. Both composites are systematically less creep resistant than monolithic zirconia. In summary, zirconia composites reinforced by graphene or carbon nanofibers do not exhibit a significant improvement of mechanical properties. The dominant effect of graphene and CNF on the creep behavior is a lubricant effect leading to the increase of grain boundary mobility.

\section{Acknowledgements}

The authors acknowledge the financial support awarded by the Regional project of Excellence of “Junta de Andalucía”P12-FQM-1079 and the Spanish MINECO and FEDER funds through the projects MAT2015-71411-R and MAT2015-67586-C3-2-R.

\section{References}

[1] S.Y. Lee, H. Kim, P.C. McIntyre, K.C. Saraswat, J.S. Byun, Atomic layer deposition of $\mathrm{ZrO}_{2}$ on W for metal-insulator-metal capacitor application, Appl. Phys. Lett. 823 (2003) 2874-2876.

[2] S. Deville, L. Gremillard, J. Chevalier, G. Fantozzi, A critical comparison of methods for the determination of the aging sensitivity in biomedical grade yttria-stabilized zirconia, J. Biomed. Mater. Res. B. Appl. Biomater. 72 (2005) 239-245.

[3] A. Domínguez-Rodríguez, D. Gómez-García, F. Wakai, High temperature plasticity in Yttria Stabilised Tetragonal Zirconia Polycrystals (YTZP), Int. Mater. Rev. 58 (2013) 399-417.

[4] M. Jiménez-Melendo, A. Domínguez-Rodríguez, A. Bravo-León, Superplastic flow of fine-grained Yttria-Stabilized Zirconia Polycrystals: constitutive equation and deformation mechanisms, J. Am. Ceram. Soc. 81 (1998) 2761-2776.

[5] K. Matsui, H. Horikoshi, N. Ohmichi, M. Ohgai, Cubic-formation and grain-growth mechanism in tetragonal zirconia polycrystal, J. Am. Ceram. Soc. 86 (2003) 1401-1408.

[6] J. Chevalier, What future for zirconia as a biomaterial? Biomaterials 27 (2006) 535-543.

[7] W.A. Curtin, B.W. Sheldon, CNT-reinforced ceramics and metals, Mater. Today. 7 (2004) 44-49.

[8] S. de Bernardi-Martín, E. Zapata-Solvas, D. Gómez-García, A. DomínguezRodríguez, F.J. Guzmán-Vázquez, J. Gómez-Herrero, On the high-temperature plasticity of ceria-doped zirconia nanostructured polycrystals, Key Eng. Mater. 423 (2009) 61-66.

[9] S. de Bernardi-Martín, D. Gómez-García, A. Domínguez-Rodríguez, G. de Portu, A first study of the high-temperature plasticity of ceria-doped zirconia polycrystals, $\mathrm{J}$ Eur. Ceram. Soc. 30 (2010) 3357-3362.

[10] J.M. Calderón Moreno, A. Ramírez de Arellano López, A. Domínguez Rodríguez, High temperature creep of alumina-zircona composites, Bol. Soc. Esp. Ceram. Vidrio 35 (1996) 345-348.

[11] C. Lorenzo, D. Gómez, A. Muñoz, A. Domínguez, R. Chaim, Creep of nanocrystalline YTZP ceramics and the influence of the glassy phase, Key Eng. Mater. 264-268 (2004) 797-800.

[12] C. Lorenzo-Martín, J.A. Flores-Vázquez, D. Gómez-García, A. Muñoz-Bernabé, A. Domínguez-Rodríguez, D. Xue Ming, J. Gómez-Herrero, Mechanical behaviour of yttria tetragonal zirconia polycrystalline nanoceramics: dependence on the glassy phase content, J. Eur. Ceram. Soc. 22 (2002) 2603-2607.

[13] B.R. Lawn, Fracture of Brittle Solids, 2nd ed., Cambridge University Press, Cambridge, United Kingdom, 1990.

[14] J.M. Calderón Moreno, A.R. De Arellano-López, A. Domínguez-Rodríguez, J.L. Routborth, High-temperature deformation of $\mathrm{ZrO}_{2}-\mathrm{Al}_{2} \mathrm{O}_{3} / \mathrm{SiC}$ whisker composites fabricated by two techniques, Mater. Sci. Eng. A 209 (1996) 115.

[15] K.I. Bolotin, K.J. Sikes, Z. Jiang, M. Klima, G. Fudenberg, J. Hone, P. Kim, H.L. Stormer, Ultrahigh electron mobility in suspended graphene, Solid State Commun. 146 (2008) 351-355.

[16] S.V. Morozov, K.S. Novoselov, M.I. Katsnelson, F. Schedin, D.C. Elias, J.A. Jaszczak, 
A.K. Geim, Giant intrinsic carrier mobilities in graphene and its bilayer, Phys. Rev. Lett. 100 (2008) 016602.

[17] C. Lee, X.D. Wei, J.W. Kysar, J. Hone, Measurement of the elastic properties and intrinsic strength of monolayer graphene, Science 321 (2008) 385-388.

[18] Y. Zhu, S. Murali, W. Cai, X. Li, J.W. Suk, J.R. Potts, R.S. Ruoff, Graphene and graphene oxide: synthesis properties, and applications, Adv. Mater. 20 (2010) 1-19.

[19] A.A. Balandin, S. Ghosh, W.Z. Bao, I. Calizo, D. Teweldebrhan, F. Miao, C.N. Lau, Superior thermal conductivity of single-layer graphene, Nano Lett. 8 (2008) 902-907.

[20] W. Cai, Y. Zhu, X. Li, R.D. Piner, R.S. Ruoff, Large area few-layer graphene/graphite films as transparent thin conducting electrodes, Appl. Phys. Lett. 95 (2009) 115-123.

[21] X. Li, Y. Zhu, W. Cai, M. Borysiak, B. Han, D. Chen, R.D. Piner, L. Colombo, R.S. Ruoff, Transfer of large-area graphene films for high-performance transparent conductive electrodes, Nano Lett. 9 (2009) 4359-4363.

[22] A.K. Geim, K.S. Novoselov, The rise of graphene, Nat. Mater. 6 (2007) 183-191.

[23] S. Park, R.S. Ruoff, Chemical methods for the production of graphenes, Nat. Nanotechnol. 4 (2009) 217-224.

[24] J. Dusza, J. Morgiel, A. Duszová, L. Kvetková, M. Nosko, P. Kun, C. Balázsi, Microstructure and fracture toughness of $\mathrm{Si}_{3} \mathrm{~N}_{4}+$ graphene platelet composite, J. Eur. Ceram. Soc. 32 (2012) 3389-3397.

[25] A. Rincón, R. Moreno, A. Chinelatto, C. Gutierrez, M.D. Salvador, A. Borrell, Effect of graphene and CNFs addition on the mechanical and electrical properties of dense alumina-toughened zirconia composites, Ceram. Int. 42 (2016) 1105-1113.

[26] F. Chen, D. Jin, K. Tyeb, B. Wang, Y.H. Han, S. Kim, J.M. Schoenung, Q. Shen, L. Zhanga, Field assisted sintering of graphene reinforced zirconia ceramics, Ceram. Int. 41 (2015) 6113-6116.

[27] J.H. Shin, S.H. Hong, Fabrication and properties of reduced graphene oxide reinforced yttria-stabilized zirconia composite ceramics, J. Eur. Ceram. Soc. 34 (2014) 1297-1302.

[28] J. Liu, H.X. Yan, M.J. Reece, K. Jiang, Toughening of zirconia/alumina composites by the addition of graphene platelets, J. Eur. Ceram. Soc. 32 (2012) 4185-4193.

[29] A. Rincón, R. Moreno, C.F. Gutiérrez-González, R. Sainz, M.D. Salvador, A. Borrell, Colloidal processing of fully stabilized zirconia laminates comprising graphene oxide-enriched layers, J. Eur. Ceram. Soc. 36 (2016) 1797-1804.

[30] E. Zapata-Solvas, D. Gómez-García, A. Domínguez-Rodríguez, Towards physical properties tailoring of carbon nanotubes-reinforced ceramic matrix composites, J. Eur. Ceram. Soc. 32 (2012) 3001-3020.
[31] S.Z. Zhongqi, S. Chen, J. Wang, G. Qiao, Z. Jin, Mechanical and electrical properties of carbon nanofibers reinforced aluminum nitride composites prepared by plasma activated sintering, J. Eur. Ceram. Soc. 31 (2011) 2137-2143.

[32] R. Cano-Crespo, B. Malmal Moshtaghioun, D. Gómez-García, A. DomínguezRodríguez, R. Moreno, Carbon nanofibers replacing graphene oxide in ceramic composites as a reinforcing-phase: is it feasible? J. Eur. Ceram. Soc. 37 (2017) 3791-3796.

[33] R. Cano-Crespo, B. Malmal Moshtaghioun, D. Gómez-García, A. DomínguezRodríguez, High-temperature creep of carbon nanofiber-reinforced and graphene oxide-reinforced alumina composites sintered by spark plasma sintering, Ceram. Int. 43 (2017) 7136-7141.

[34] A. Duszová, J. Dusza, K. Tomásèk, J. Morgiel, G. Blugand, J. Kueblerd, Zirconia/ carbon nanofiber composite, Scr. Mater. 58 (2008) 520-523.

[35] J. Dusza, G. Blugan, J. Morgiel, J. Kuebler, F. Inamd, T. Peijs, M.J. Reece, V. Puchy, Hot pressed and spark plasma sintered zirconia/carbon nanofiber composites, J. Eur. Ceram. Soc. 29 (2009) 3177-3184.

[36] A. Rincón, A.S.A. Chinelatto, R. Moreno, Tape casting of alumina/zirconia suspensions containing graphene oxide, J. Eur. Ceram. Soc. 34 (2014) 1819-1827.

[37] A. Rincón, R. Moreno, A.S.A. Chinelatto, C.F. Gutiérrez, E. Rayón, M.D. Salvador, A. Borrell, $\mathrm{Al}_{2} \mathrm{O}_{3}-3 \mathrm{YTZP}-\mathrm{Graphene}$ multilayers produced by tape casting and spark plasma sintering, J. Eur. Ceram. Soc. 34 (2014) 2427-2434.

[38] J.C. Durand, B. Jacquot, H. Salehi, M. Fages, J. Margerit, F.J.G. Cuisinier, Confocal Raman Microscopic Analysis of the zirconia/feldspathic Ceramic Interface, Dent Mater. 28 (2012) 661-671.

[39] S. Nazarpour, C. López-Gándara, C. Zamani, J.M. Fernández-Sanjuán, J.M. Ramos, A. Cirera, Phase transformation studies on YSZ doped with alumina. Part 2: yttria segregation, J. Alloys. Compd. 505 (2010) 534-541.

[40] L.M. Malard, M.A. Pimenta, G. Dresselhaus, M.S. Dresselhaus, Raman spectroscopy in graphene, Phys. Rep. 437 (2009) 51-58.

[41] M.S. Dresselhaus, A. Jorio, M. Hofmann, G. Dresselhaus, R. Saito, Perspectives on carbon nanotubes and graphene Raman spectroscopy, Nano Lett. 10 (2010) $751-758$

[42] M.T. Laugier, New formula for indentation toughness in ceramics, J. Mater. Sci. Lett. 6 (1987) 355-356.

[43] D. Gómez-García, E. Zapata-Solvas, A. Domínguez-Rodríguez, L.P. Kubin, Diffusiondriven superplasticity in ceramics. Modeling and comparison with available data, Phys. Rev. B 80 (2009) 2141071-2141078. 